\title{
5 Um retrato de Fellini como artista
}

Euclides Santos Mendes*

Resumo

O cineasta italiano Federico Fellini aprendeu o ofício de roteirista nos anos 1940, enquanto colaborava em filmes neorrealistas, e o manteve ao longo da sua vida. Consagrou-se internacionalmente como diretor no início dos anos 1960, ao transformar seu primevo olhar de matriz neorrealista numa reelaboração realístico-subjetiva. Fellini, por meio do neorrealismo, levou a imagem puramente ótica e sonora para além do neorrealismo, moldando-a, segundo o filósofo Gilles Deleuze, como um cristal de tempo.

Palavras-chave: Cinema Italiano, Federico Fellini, Neorrealismo, Gilles Deleuze.

\section{Abstract}

The Italian filmmaker Federico Fellini learned the art of screenwriting in the 1940s, while collaborating in neorealist movies, and mantained it throughout his life. $\mathrm{He}$ established himself internationally as a director in the early 1960s, when he transformed his primal neorealist matrix approach into a subjective-realist reelaboration. Through neorealism Fellini took the pure opticalsound image beyond the neorealism, shaping it as a crystal of time, according to the philosopher Gilles Deleuze.

Keywords: Italian Cinema, Federico Fellini, Neorealism, Gilles Deleuze. 


\section{Do sonho à poesia}

Desde a infância e a adolescência em Rimini, cidade italiana

${ }^{1}$ Que esteve em cartaz no IMSRJ, de 10 de março a 17 de junho de 2012, e no Sesc Pinheiros, em São Paulo, de 3 de julho a 6 de setembro de 2012. na costa do mar Adriático onde nascera, Federico Fellini (1920-93) apreciava caricaturas, charges e histórias em quadrinhos. Tornou-se desenhista precocemente; tal atividade lhe rendeu as primeiras
Fellini, seguido do doutor Ernst Bernhard, descobre os estudos de Jung e se familiariza com suas teorias sobre a análise dos sonhos e sobre a ideia do inconsciente coletivo. Inicia então um trabalho meticuloso de retranscriação de seus sonhos por meio do desenho e da escrita, exercício ao qual ele se submete até 1990. Fellini se entusiasma pelo pensamento de Jung, pois ele oferece uma estrutura a suas explorações cinematográficas. oportunidades para conquistar a própria independência.

No começo dos anos 1960, o talento para desenhar transformou-se numa terapia: aconselhado pelo psicanalista junguiano Ernst Bernhard, com quem passara a se consultar, Fellini decidiu desenhar os próprios sonhos. Quase todas as manhãs, assim que despertava, punha-se a registrar efusivamente as lembranças da noite onírica. Manteve esse hábito até 1990; quando se deu por satisfeito, possuía três livros-álbuns preenchidos por imagens coloridas e voluptuosas, com histórias carregadas de simbolismo. Segundo Sam Stourdzé (2012, p. 12), curador da exposição “Tutto Fellini",
Após a morte do diretor, em 1993, dois dos livros-álbuns - o terceiro desapareceu - foram trancados no cofre de um banco italiano, salvaguardado da disputa entre os herdeiros de Fellini e de sua mulher, a atriz Giulietta Masina (morta em 1994). Em 2006, após um acordo que envolveu a Fundação Federico Fellini (sediada em Rimini), o governo da Emilia Romagna (região italiana onde Fellini nasceu) e os herdeiros de Giulietta, os enigmáticos livros foram, enfim, abertos e apresentados publicamente como um precioso instrumento para ajudar a compreender a estilística e a poética do diretor italiano.

Acredita-se que alguns dos mais característicos personagens nascidos da experiência criativa felliniana tiveram seu primeiro sopro de vida nas recordações e desenhos que o cineasta registrava no seu Libro dei Sogni (Livro dos Sonhos). Tal obra, publicada na França e na Itália, é um tipo de registro diretamente relacionado ao modo de criação artística por meio do inconsciente e da subjetividade. Ao que se supõe, há nos desenhos do Livro dos 
Sonhos impulsos profundos de criação sensível de personagens e episódios, alguns recriados na tela cinematográfica.

Parece indubitável que haja uma relação de experiência ambígua entre a imagem cinematográfica e a maneira como os sonhos se revelam enquanto dormimos. Um Cão Andaluz (Le Chien Andalou, 1929, de Luis Buñuel e Salvador Dalí), filme criado a partir de sonhos dos seus realizadores, bem expressa tal intenção, como explica o cineasta e escritor italiano Pier Paolo Pasolini (1982, p.143), no ensaio $O$ “cinema de poesia”, de 1965:

É certo que existem casos-limite. Onde a poeticidade da linguagem se torna evidente até a loucura. Le Chien Andalou, de Buñuel, por exemplo, é abertamente construído segundo um registro de expressividade pura: mas, para o efeito, Buñuel socorreu-se do prontuário sinalético do surrealismo. E convém dizer que, enquanto produto surrealista, é sublime. Poucas obras surrealistas, tanto literárias como de pintura, podem comparar-se-lhe, porque a sua qualidade poética foi contaminada e tornada irreal pelo seu conteúdo, ou seja: pela poética do surrealismo, que é uma espécie de conteudismo bastante brutal (é por isso que as palavras e as cores perdem a sua pureza expressiva, para se submeterem a uma monstruosa impureza de conteúdo). A pureza das imagens cinematográficas é, pelo contrário, exaltada em lugar de diminuída por um conteúdo surrealista. Porque o surrealismo reintroduz no cinema a natureza onírica do sonho e da memória inconsciente etc. etc.

Seria, aqui, um óbvio equívoco relacionar frontalmente Fellini e o surrealismo. O que interessa é, sobretudo, a relação entre sonho, inconsciente e arte. Em Oito e Meio (Otto e Mezzo, 1963), obra que reafirma o gênio criativo felliniano, o cineasta traz o mundo onírico a primeiro plano ao tentar explicar as motivações do protagonista, o cineasta Guido, naquilo, em suma, que o crítico italiano Ennio Bispuri (2003, p. 109) qualificou como "o sonho de onipotência de um impotente". Não se sabe ao certo se os registros imagéticos do Livro dos Sonhos têm relação direta com a criação de Oito e Meio. O Livro dos Sonhos é uma obra ainda a ser devidamente estudada. Vale observar, no entanto, que há uma camada onírica essencial no enredo do filme.

A arquitetura visual de Oito e Meio circula pelo inconsciente do protagonista, em que os sonhos se apresentam como assombrosas sequências, mas também avança pela memória decodificada do personagem e pelo tempo presente. Para a crítica de arte e ensaísta 
Gilda de Mello e Souza (2008, p. 177-178), o filme cria uma narrativa livre, com características que o tornam uma "obra aberta" e o lança na linha de vanguarda da narrativa contemporânea.

Oito e Meio pode não ser a realização mais alta e mais perfeita de Fellini, mas é sem dúvida, tanto do ponto de vista estrutural quanto de significado, o filme que sugere à crítica os problemas mais fascinantes. Ao construir uma narrativa livre, dissolvendo o entrecho linear numa certa atemporalidade, Fellini se inscreveu na linha de vanguarda da narrativa contemporânea, sobretudo na linha do "nouveau roman", que havia atingido o cinema em obras como Hiroshima, Meu Amor [1959], O Ano Passado em Marienbad [1961], Morangos Silvestres [1957]. À primeira vista, Oito e Meio apresenta, pois, aquelas características de "obra aberta", como define Umberto Eco, que fazem explodir a estrutura tradicional do enredo para "mostrar uma série de acontecimentos carentes de nexo dramático no sentido tradicional". Contudo, se o seu processo narrativo não obedece à tradição e desrespeita o tempo cronológico do relógio, não deixa, por outro lado, de estabelecer um tempo particular, que chamarei de tempo subjetivo de Guido, personagem central, e que nasce da intersecção de dois planos: o plano horizontal do presente e o plano vertical das lembranças do passado, dos sonhos, dos devaneios e das aspirações mais profundas.

Em Oito e Meio, o "tempo subjetivo de Guido" compõe uma espécie de autorretrato multifacetado do personagem, que incorpora a ideia do artista no confronto mais denso com seu processo criativo. Ao olhar para si e para o mundo com os meios que a consciência e o inconsciente lhe oferecem, Guido mergulha no seu tempo interior. Em sua análise de Oito e Meio, Gilda de Mello e Souza (2008, p. 180) reconhece no imaginário do personagem a chave que lhe abre as portas da infância, da fantasia, da memória e dos sonhos.
Dossiê Cinema e Audiovisual: entre o sensível e o reflexivo Arquivos do CMD, Volume 3, N. 1. Jan/Jul 2015
As cenas iniciais do filme são, nesse sentido, exemplares, e a queda de Guido, do céu em que flutua como um enorme espantalho ao mar, nos adverte o que será o filme: um mergulho no seu ser mais profundo. $\mathrm{O}$ devassamento impiedoso irá questionar tudo: o comportamento no amor, o processo pessoal da criação, as angústias religiosas. E a chave de tudo estará na infância, ou nos sonhos e devaneios do adulto (SOUZA, 2008, p. 180). 
O crítico e ensaísta Roberto Schwarz (1981, p. 194) também vê na estrutura atemporal de Oito e Meio o sinal e, por conseguinte, o caminho para o mergulho simbólico na "alma" do protagonista:
Se Fellini é Guido, os conflitos deste campeiam idênticos no peito daquele, que seria o bobo de suas próprias limitações, um pequeno-burguês nostálgico e fantasioso, incapaz de fazer qualquer coisa que preste.
Guido circula ativamente entre presente, memória e fantasia. As senhas de passagem são geralmente detalhes visuais, e a origem do movimento é o instante do adulto. A matriz dos significados, entretanto, está nas imagens da infância, cuja força e anterioridade lógica faz delas como que o lastro real da inquietação de Guido. Os dilemas do adulto aparecem como variação mais ou menos disfarçada de contradições antigas, de uma ambiguidade fundamental: a Saraghina é o mal, mas é o bem, e a mãe [de Guido] e os padres são o bem, mas são o mal.

O crítico adverte, todavia, ser um artifício enganoso o espelhamento que costumeiramente se faz entre Fellini e Guido, identificação "autorizada pelos colunistas de mexerico, pelo próprio diretor, talvez, mas não pelo filme" (SCHWARZ, 1981, p. 191). Escreve Schwarz (1981, p. 191):
A potência subjetiva de Oito e Meio é reveladora de um gesto maior, que certamente vai além da psicologia do diretor e avança pelo campo do imaginário na criação artística, como um tratado poético em forma de imagens, cujo pensamento, vivo e pulsante, alcança densidade poética. É como se o filme e o gesto de pensá-lo ao fazê-lo criassem, em película, a experiência de uma aventura maravilhosa, em que o mundo da memória e o dos sonhos se manifesta por meio de imagens "significantes". De acordo com Gilda de Mello e Souza (2008, p. 208), “apesar das dúvidas e indecisões, avanços e recuos, foi para a aventura de saltar da torre no espaço vertiginoso da arte que Guido se preparou longamente" e, portanto, "o filme de Fellini é a fenomenologia deste gesto frágil e arriscado".

De onde vem, contudo, a fragilidade e o risco apontados por Gilda? Talvez da própria tentativa de construção imagéticodiscursiva do "cinema de poesia" em Fellini. O termo "cinema de 
2 O termo "cinema de poesia" advém do conceito de "subjetiva indireta livre", formulado por Pasolini a partir do conceito de "discurso indireto livre", do teórico russo Mikhail Bakhtin, e cumpre, segundo o filósofo Roberto Machado (2009, p. 286287), o papel de "ultrapassar subjetivo e o objetivo da percepção por uma forma pura que se erige em visão autônoma do conteúdo, correlacionando uma imagem-subjetiva e uma imagem-objetiva, em que a últim transforma a primeira no sentido de produzir uma reflexão da imagem numa consciênciacâmera, numa câmera consciência de si. Uma imagem-subjetiva seria um discurso direto: espectador vê o que o personagem vê. Uma imagem-objetiva, um discurso indireto: o espectador vê o personagem e sabe o que ele está vendo. O cinema de poesia de Pasolini é baseado num discurso indireto livre que consiste, diz Deleuze, 'numa enunciação tomada em um enunciado que nor cul vag dananda da nutra

Dossiê Cinema e Audiovisual: entre o sensível e o reflexivo Arquivos do CMD, Volume 3, N. 1. Jan/Jul 2015 poesia", ${ }^{2}$ tal como pensado e analisado por Pasolini, relaciona-se com o uso da "subjetiva indireta livre", meio narrativo derivado do discurso indireto livre usado na literatura, em que o autor manifesta suas ideias, sentimentos e perspectivas de mundo por meio da psicologia dos personagens e da poética inerente ao discurso cinematográfico.

O "cinema de poesia" - tal como se apresent poucos anos depois do seu nascimento - tem assim como característica comum a produção de filmes dotados de uma dupla natureza. O filme que se vê e se aceita normalmente é uma "Subjectiva Indirecta Livre", por vezes irregular e aproximativa - muito livre, em suma: o realizador serve-se do "estado de alma psiquicamente dominante do filme" -, que é o de um protagonista doente, anormal, a partir do qual opera uma mimésis contínua - o que lhe permite uma grande liberdade estilística, anómala e provocatória. Por baixo desse filme, corre o outro filme - o filme que o autor teria feito mesmo sem o pretexto da mimésis visual do seu protagonista: um filme de carácter inteira e livremente (PASOLINI, 1982, p. 149).
De acordo com Pasolini, o "cinema de poesia" é alimentado pelo "exercício de estilo como inspiração, na maior parte dos casos, sinceramente poética". A estilística e a poética cinematográficas revelam, assim, camadas de subjetividade que se formam segundo a intensidade com que uma obra mergulha no seu processo de subjetivação. A memória e os sonhos são exemplos de tais camadas, e suas manifestações se dão como processos que descortinam indícios sobre a formação do imaginário.

\section{Pasolini (1982, p. 138-139) defende que}

o instrumento linguístico sobre o qual se implanta o cinema é, por isso, de tipo irracionalista: eis o que explica a qualidade onírica profunda do cinema e também a sua absoluta e imprescindível concreção, digamos, objectal.

Daí ser possível encontrar no pensamento crítico de Pasolini uma possibilidade de explicação teórica relacionando Fellini ao "cinema de poesia", pois

o cinema é fundamentalmente onírico pela elementaridade dos seus arquétipos [...] e pelo 
prevalecer fundamental no seu âmago da prégramaticalidade dos objectos como símbolos da linguagem visual (PASOLINI, 1982, p. 141).

Os arquétipos em Oito e Meio se manifestam, como sugere Gilda de Mello e Souza (2008, p. 199), graças à presença subjetiva de "duas Vênus antagônicas, dois Eros de natureza diversa, o Amor divino e o Amor bestial", que, no filme em questão, estariam encarnados na mãe e na Saraghina, respectivamente.

A existência contraditória de Guido evidencia a experiência do impasse no filme como gesto criativo complexo. O personagem é uma espécie de álibi narrativo usado por Fellini para tecer seu argumento poético na medida em que ele expressa em Guido condições análogas - e, por isso, enganosas numa relação direta de identificação - na cultura e na psicologia, como requintados atributos de onde ecoa a voz do cineasta de Rimini.

Dossiê Cinema e Audiovisual: entre o sensível e o reflexivo Arquivos do CMD, Volume 3, N. 1. Jan/Jul 2015 Oito e Meio $\mathrm{E}$ o filme que é mais próximo, pela sua estrutura formal, à grande literatura europeia do Novecentos, de Joyce a Proust, de Kafka a Musil, antes de tudo porque se apresenta como uma busca das causas que levam o autor a não poder se exprimir, depois pela sua articulação no plano de um monólogo interior no qual tudo conflui desordenadamente, desnudando aquilo que banalmente pode ser considerado o mecanismo interrompido da consciência no seu fluir desordenado, e ainda por centrar-se, no fundo, sobre um uomo senza qualità [...] (BISPURI, 2003, p. 108).

Para um diretor como Fellini, cuja estilística e poética tornam-se identificáveis no uso de marcas de roteiro, cenário e trilha sonora, entre outros atributos de composição da mise-en-scène, há uma relação conceitual de sua obra com o "cinema de poesia". A voz poética, que confere ao diretor uma liberdade fora do comum no trato com o objeto fílmico, pode ameaçar a integridade da obra quando, de uma inspiração imprevista, emerge experiências de memória que parecem se suceder na montagem. Este, porém, não é $\mathrm{o}$ caso de Fellini. De seu manancial barroco eis que vem à tona $\mathrm{o}$ exercício do estilo como inspiração, além da mais ampla liberdade poética possível em meio ao turbilhão atemporal de micronarrativas presentes no filme.

No primeiro Fellini (ou seja, nos primeiros filmes dirigidos por ele, nos anos 1950), há já patente a presença da força do estilo, decorrente de sua "atitude neorrealista" no confronto com a 
experiência do cinema. $\mathrm{O}$ esforço de reconstrução da memória, por exemplo, no filme Os Boas-Vidas (I Vitelloni, 1953) garante muito mais a necessidade de narrar episódios da vida provinciana inspirados em Rimini do que mergulhar os personagens no pensamento poético-subjetivo do cineasta. A partir de A Estrada da Vida (La Strada, 1954), Fellini demonstra domínio criativo mais apurado, evidenciando qualidades narrativas ao propor a fábula de Gelsomina e Zampanò.

É, contudo, com A Trapaça (Il Bidone, 1955) e, principalmente, com Noites de Cabíria (Le Notti di Cabiria, 1957) que o cineasta alça sua capacidade estilística a um patamar poético que não depende tão somente do valor que a história assume como fábula. Em A Trapaça, Fellini cria aquele que, entre os seus filmes, é um dos que mais se aproximam de uma temática tratada segundo preceitos neorrealistas (sobretudo pelo contexto de fundo social, pelas cenas filmadas em ambientes naturais e pelo uso de não atores). $\mathrm{O}$ cineasta faz disso uma experiência de passagem para a afirmação da sua estilística.

Com Noites de Cabíria nasce a marca do artista mergulhado na própria criação, um ser profundamente ligado à concepção poética das suas criaturas. A personagem Cabíria revela, talvez, o contraponto poético mais intenso à verve onírica do personagem Guido, de Oito e Meio. Ambos estão em processo de subjetivação, como Fellini. A poesia se institui definitivamente na obra do cineasta no momento em que a prostituta romana dá as caras - isso ocorrera em Abismo de um Sonho (Lo Sceicco Bianco, 1951) - e age num mundo socialmente identificável com o da Itália do pré-boom econômico.

O personagem Marcello, em A Doce Vida (La Dolce Vita, 1960) reverbera ainda mais intensamente essa visão do mundo social romano. Porém Guido, num ambiente marcado pela decadência e pelo posterior reencontro moral, talvez seja o ápice da experiência de confronto do cineasta com a criação cinematográfica tal como pensada pelo "cinema de poesia”. É por meio da expressão ambígua e desnorteante de Guido que se evidencia o sentido da formação individual, pois Oito e Meio se resume nisto: é como Fellini torna-se cineasta.

\section{Do tempo à realidade}

Os anos de aprendizado e os de experiência neorrealista de Federico Fellini, respectivamente nos anos 1940 e 1950, confluíram na ascensão de um artista, filho e herdeiro de uma tendência 
estético-narrativa destinada a cultivar a sagração da realidade como espelho do mundo deformado do tempo. O tempo, porém, é só uma margem, e não a realidade. O tempo é a morte e preserva o que a realidade tem de eterno.

Narrar o real é, portanto, narrar o tempo em sua transfiguração. De acordo com Gilles Deleuze (2007, p. 99), no cinema vê-se a fundação do tempo na formação imagem-cristal, cuja "irredutibilidade consiste na unidade indivisível de uma imagem atual e de 'sua' imagem virtual". Trata-se do tempo não cronológico, em estado puro, como forma imutável do que muda, em que o cristal impede a sua subordinação ao movimento e revela uma imagem-tempo direta. A imagem-tempo como fruto do cristal em formação é possível por meio da vidência do personagem visionário capaz de entrever simultaneamente o presente (imagem atual) e o passado ou o sonho (imagem virtual). Segundo Roberto Machado (2009, p. 279-280),

o que o visionário, o vidente vê no cristal, com seus sentidos libertados, é o tempo, é o jorro do tempo como desdobramento, como cisão em presente e passado, presente que passa e passado que se conserva: o tempo em sua diferenciação.
Se, desde os seus primeiros filmes, Fellini representou a vida cotidiana como um espetáculo, foi no sentido de revelar a narrabilidade do eu como consciência histórica, isto é, consciência da existência que transfigura o tempo. Realidade e espetáculo se fundem progressivamente na filmografia felliniana, gerando cristais de tempo que atingem o êxtase na sarabanda romana de $A$ Doce Vida, mas também na supercaricatura do protagonista do médiametragem As Tentações do Doutor Antonio (Le Tentazioni del Dottor Antonio, 1962, um dos quatro episódios do filme coletivo Boccaccio'70) e no grande circo final de Oito e Meio.

Já em Fellini, esta ou aquela imagem é subjetiva, mental, lembrança ou fantasma, mas não se organiza como espetáculo sem se tornar objetiva, sem entrar nos bastidores, na "realidade do espetáculo, daqueles que o fazem, vivem dele, se arranjam com ele": o mundo mental de uma personagem povoa-se tão bem com outros personagens proliferantes que se torna intermental, e chega por aplainamento das perspectivas, "a uma visão neutra, impessoal [...], o mundo de todos nós" [...] (DELEUZE, 2007, p. 17) 
Na obra decorrente da experiência neorrealista felliniana, a narrabilidade fílmica propõe o desmoronamento de esquemas sensório-motores, cedendo lugar a situações óticas e sonoras puras em que um personagem torna-se visionário ao mesclar presente e passado, experiência e memória. Moraldo, Gelsomina, Augusto, Cabíria, Marcello, Guido: visionários da outra margem do rio cinematográfico, personagens de uma verdade revelada pelo tempo, a de que o mistério final se resume a nós mesmos. Eis aí uma marca que faz do cinema felliniano uma vertente do cinema moderno, em que o sujeito adquire centralidade narrativa e fenomenológica.

O liame do homem e do mundo é o impossível, o impensável que só pode ser objeto de crença. E, se apenas a crença no mundo pode religar o homem que perdeu a capacidade de reação ao que ele vê e ouve, o poder do cinema moderno é dar novamente ao homem a crença no mundo. Com o cinema moderno é possível acreditar nesse liame como no impensável que precisa ser pensado - crença que faz do impensado a potência própria do pensamento; é possíve servir-se da impotência do pensamento para acreditar na vida e encontrar a identidade do pensamento e da vida (MACHADO, 2009, p. 288)

Dossiê Cinema e Audiovisual: entre o sensível e o reflexivo Arquivos do CMD, Volume 3, N. 1. Jan/Jul 2015
Ao furar o bloqueio culturalista italiano, Fellini alcançou a outra margem do tempo, em que a realidade, o espetáculo e o sonho se fundem numa catarse, pois são objetos da formação de um indivíduo: o próprio Fellini, um Wilhelm Meister italiano cuja missão cinematográfica o conduziu aos anos de aprendizado neorrealista - período de enfrentamento de ambiguidades e, por isso, processo de contínuas transformações - e aos de experiência que se revelam como tempo de peregrinação à matriz neorrealista. $\mathrm{O}$ neorrealismo foi um fenômeno determinante na formação de Fellini e do cinema moderno italiano, dando-lhe a feição de um espelho fragmentado da realidade.

Para o cineasta e crítico Glauber Rocha (1983), "Rossellini documenta as ruínas", ao passo que Fellini, "documentarista do sonho", "o recria magicamente através de cenografias e atores, o sonho é a projeção de sua Câmera Olho". A observação de Glauber reafirma certo caráter do cinema felliniano como um mundo onírico invisível, apesar de sua visibilidade cinematográfica, um mundo quase louco, pois é completo mesmo sendo apenas parcial.

A Doce Vida é esse mundo no limiar de um abismo, mas quem cai nele é Fellini. Ele dá adeus à escola neorrealista, onde se formou desde o filme-manifesto Roma, Cidade Aberta (Roma Città 
Aperta, 1945, de Roberto Rossellini) e mergulha na poesia do próprio cinema, retornando ao magma neorrealista originário, mas, dessa vez, para moldá-lo como artifício da sua própria expressão artística e cinematográfica. Daí Oito e Meio ser o confronto do artista com sua subjetividade mais real e, por isso, também um exame de maturidade.

\section{Referências}

BISPURI, Ennio. Interpretare Fellini. Rimini: Guaraldi, 2003.

DELEUZE, Gilles. A Imagem-Tempo. Tradução de Eloisa Araújo Ribeiro. São Paulo: Brasiliense, 2007.

MACHADO, Roberto. "Deleuze e o cinema". In: Deleuze, a Arte e a Filosofia. Rio de Janeiro: Zahar, 2009, p. 245-296.

PASOLINI, Pier Paolo. "O 'cinema de poesia"”. In: Empirismo Hereje. Lisboa: Assírio e Alvim, 1982, p. 137-152.

ROCHA, Glauber. $O$ Século do Cinema. Rio de Janeiro Alhambra/Embrafilme, 1983.

SCHWARZ, Roberto. "8 1/2 de Fellini - O menino perdido e a indústria”. In: A Sereia e o Desconfiado - Ensaios Críticos. Rio de Janeiro: Paz e Terra, 1981, p. 189-204.
SOUZA, Gilda de Mello e. "O salto mortal de Fellini". In: Exercícios de Leitura. São Paulo: Duas Cidades/Editora 34, 2008, p. 177-208.

STOURDZÉ, Sam (org.). Tutto Fellini. Tradução de Cecília Ciscato e Samuel Titan Jr. Rio de Janeiro/São Paulo: Instituto Moreira/Sesc, 2012 